\title{
Understanding the Effects of Forage Composition and Structure in Ruminant Nutrition ${ }^{1}$
}

\author{
Kalyn M. Waters, Nicolas DiLorenzo, and G. Cliff Lamb²
}

\section{Introduction}

Approximately $68 \%$ of the 16 million square miles of agricultural land worldwide is used for permanent pastures for livestock production. Fortunately, ruminants can convert plant matter that is inedible or of low nutritional value for monogastrics (i.e., swine or poultry) into calorically dense products of high nutritional value. However, the process of converting poor quality plant matter into useful nutrients for ruminants is complex. Therefore, the goal of this publication is to provide an overview and understanding of how forage composition and structure affect the nutritive value and nutrient availability to ruminants.

\section{Forage Type}

Forages tend to have crude fiber concentrations greater than $18 \%$; however, the nutritional composition of the plant is highly dependent upon the stage of growth, maturity, and species. Forage types used in ruminant production are commonly segmented into two categories, legumes and grasses. Currently, more than 14,000 legume species and 6,000 grass species are used in livestock production around the world (Pond et al. 2005). Grasses tend to be the most abundant forage component of livestock nutrition. For practical purposes, forages are typically classified as warm season or cool season, but the true classification is based on their physiology, as either $\mathrm{C} 4$ (mostly warm-season forages) or C3 (mostly cool-season forages) species. The C3 or C4 denomination for grasses is related to the type of photosynthesis and leaf structure they have, which directly relates to forage digestibility and quality. Legumes have seeds born in pods and compound leaves with multiple leaflets. They also have the unique ability to fix gaseous nitrogen from the atmosphere and convert it into ammonia and plant protein. This feature allows them to grow successfully in many environments.

Animals consuming legumes tend to have increased forage voluntary dry matter intake compared to those consuming grasses. This is due to the faster rate of digestion; legumes can pass through the rumen at an increased rate, reducing the fill effect and allowing the animal to consume more feed. Legumes have less cell wall content, which is where most of the fiber is located, and this allows for increased digestibility. However, the extent at which the cell wall is digested is typically greater for grasses than for the cell wall of legumes (West et al. 1999). In addition, legumes tend to have greater concentrations of macro minerals (e.g., calcium, phosphorous) and micro minerals (e.g., copper, iron, etc.) when compared to grasses. Grasses have more hemicellulose than legumes, which is why the potential digestibility of the cell wall is greater than that of legumes.

1. This document is AN288, one of a series of the Department of Animal Sciences, Florida Cooperative Extension Service, Institute of Food and Agricultural Sciences, University of Florida. Original publication date March 2013. Visit the EDIS website at http://edis.ifas.ufl.edu.

2. Kalyn M. Waters, cow-calf field specialist, South Dakota State University Extension, Winner, SD; Nicolas DiLorenzo, assistant professor, Department of Animal Sciences, North Florida Research and Education Center, Marianna, FL; and G. Cliff Lamb, professor, Department of Animal Sciences, North Florida Research and Education Center, Marianna, FL; Florida Cooperative Extension Service, Institute of Food and Agricultural Sciences, University of Florida, Gainesville, FL 32611. 


\section{Cell and Cell Wall Structure}

Forages are constructed of cells, which have a lumen and cell wall. The lumen is the inner part of the cell where the starch, sugars, and proteins are housed. The space between cells is the middle lamella, a structural polysaccharide high in pectin that binds plant cells together, similar to cement between bricks (Pond et al. 2005).

Cell walls are composed of cellulose, hemicellulose, lignin, and pectin; all of which are polysaccharides. Polysaccharides are complex structures that contain molecules whose biosynthesis is controlled by genetic and enzyme coding. Livestock nutritionists have simplified the analysis of forages' cell wall components to be able to assess nutritive value. Van Soest (1964) developed an analysis called Neutral Detergent Fiber (NDF), which is a fiber fraction obtained using detergents to remove all the forage material except the cell wall.

The main components of NDF are cellulose, hemicellulose, pectin, and lignin. If the NDF residue is further washed with an acid detergent, Acid Detergent Fiber (ADF) is obtained. ADF contains cellulose and lignin and represents the most indigestible fiber fraction of forages. Cellulose consists of a linear chain of glucose (sugar) units with $\beta$ 1-4 linkages. These linkages are broken by cellulase, an enzyme produced by microorganisms within the rumen. Once cellulase breaks the glucose linkages, the microorganisms in the rumen can have access to the polysaccharides in the cell's interior (Hungate 1966). Hemicellulose is a more complex structure, with several different types of sugars bound by a 1-4 linkages and is closely associated with lignin. The hemicellulose is highly digestible if it is not lignified.

\section{Lignin}

Lignin is the major component of the cell wall that limits digestion of plant matter polysaccharides. Therefore, lignin concentration, composition, and structure all play a critical role in rumen digestion. Lignin is a polymer of hydroxycinnamyl alcohols, which are deposited in the plant cell wall (Jung and Allen 1995). As the plant matures, lignin content increases and the location of deposition changes. Typically, grasses accumulate lignin in their stems as they mature, while legumes do not accumulate as much. This allows legumes to be harvested at more advance maturity stages (e.g., flowering) without compromising forage quality. Increased lignin concentrations decrease ruminants' ability to digest forage.

The negative association between lignin concentration and digestibility has been understood for years. Digestion is limited when the polysaccharides are shielded from enzymatic hydrolysis by lignin. Lignin is negatively associated with the extent of NDF digestion; therefore, as lignin concentrations increase, an overall decrease in forage digestibility is noted. In addition, the effect of lignin on fiber digestion is greater in grasses than in legumes.

As forages mature, the lignin concentration increases, and there is a shift in the type of lignin being deposited. While concentration and type are important, the cross-link of lignin to polysaccharides is the greatest determining factor for digestibility. When lignin is cross-linked to the polysaccharides of the plant cell wall (mainly hemicellulose), digestion is dramatically decreased. This cross-link forms a barrier that limits microbial access to polysaccharides to begin the digestion process.

\section{Plant Growth}

Primary cell wall growth takes place as the plant increases in size, with an increased deposition of xylans (a complex polysaccharide found in the cell wall), polysaccharides, hemicellulose, and cellulose; however, little lignin deposition occurs during this primary growth stage. After the primary growth stage concludes, a switch toward the secondary wall thickening occurs. At this point, the cell wall becomes progressively thicker, growing from the inner edge of the wall toward the center of the plant. During the secondary growth phase, additional polysaccharides are deposited and lignin deposition starts.

A secondary cell wall formation begins once the cell completes its elongation and growth. Lignin begins to be incorporated into the cell wall in the middle lamella, the space between plant cells, and progresses inward through the secondary wall toward the lumen. The cross-link between polysaccharides and lignin starts to take place in the secondary phase of plant growth. Since intake of ruminants is limited by the rate at which dry matter (DM) exits the rumen, plant cell walls and the extent of lignification contributes to decreased intake. Thus, as the forage matures, the extent of digestibility decreases, along with the rate of digestion and passage through the rumen.

\section{Energy}

The energy value of forages is related to their ability to be digested and transformed into the simple sugars that rumen microorganisms can use for growth. Energy values of feed are most commonly expressed as total digestible nutrients (TDN), which includes a correction for digestible protein. Digestible energy (DE) can be converted into TDN using 
the following equation: $1 \mathrm{~kg}(2.2 \mathrm{lb})$ of $\mathrm{TDN}=4.4 \mathrm{Mcal}$ of DE. Metabolizable energy (ME) deducts the energy that will be lost to feces, urine, and gases from DE. Thus, ME is an estimate of the feed's available energy for maintenance and growth.

Forages are comprised mostly of structural carbohydrates. Serving as a major source of energy, carbohydrates are found in plants as sugar molecule chains. These sugar molecules include ribose and glucose, both simple sugars (Pond et al. 2005). Structural carbohydrates are broken down by the rumen microbes. Then the simple sugars are converted into compounds used to support the rumen microbial population, which sustains digestion and animal metabolism. As microbes digest the feedstuffs, by-products called volatile fatty acids (VFA) are produced. These VFA produced by the microbes serve as a major energy source for the ruminant animal, creating a perfect symbiotic relationship between microbes and ruminants.

The fiber content of feed can be used to help estimate the energy value. In cool-season forages, $\mathrm{ADF}$ content is a good indicator of the forage's TDN, while NDF (a regulator of forage intake) may be used to estimate net energy for lactation, maintenance, and gain. Conversely, in warmseason forages, the ability to predict TDN and intake from $\mathrm{ADF}$ and NDF is not great due to the complex structure of C4 forages (Moore et al. 1999). In general, as the NDF decreases, the net energy content of forage will increase, but this is highly specific to forage type.

\section{Protein}

Crude protein (CP) is determined by analysis of the forage's nitrogen content. The $\mathrm{CP}$ value of a feed does not give the feed's actual protein content. Rather, on average, proteins contain $16 \%$ nitrogen; thus, determining the amount of nitrogen in the organic matter is a reliable means to determine CP. The CP in a forage or feedstuff can be segmented into degraded intake protein (DIP), soluble intake protein (SIP, usually considered a fraction of DIP), and undegradable intake protein (UIP). The SIP is rapidly broken down in the rumen and utilized by rumen microbes. DIP is degraded at a slower rate, but degradation also occurs in the rumen and provides additional nitrogen sources for microorganisms. Undegradable intake protein is also known as rumen undegradable protein (RUP) or by-pass protein, and is the fraction of CP not degraded prior to entering the small intestine.

Depending on the stage of maturity, legumes tend to have greater concentrations of $\mathrm{CP}$ than grasses. Protein content of legumes conserved as hay depends on the leaf:stem ratio. Also, most of the protein is present in the leaves, which can be easily lost during the hay-making process.

\section{Conclusion}

While forage type and species play key roles in the quality and nutritive value of forages, much variation can be found between and within these groups. Growth and maturity stages are critical contributors to altering digestibility with lignin content and its linkage to polysaccharides increasing as plants age. Therefore, evaluating digestibility, quality, and energy content of the forage is essential to plan proper supplementation strategies when needed. By understanding forage structure and composition, producers can better manage the roughage component of their ruminant's diet. For additional information about forage quality, see EDIS publication AG161/SS-AGR-93 Factors Affecting Forage Quality (http://edis.ifas.ufl.edu/ag161).

\section{References}

Hungate, R.E. 1966. The Rumen and Its Microbes. New York: Academic Press.

Jung, H. G., and M. S. Allen. 1995. "Characteristics of Plant Cell Walls Affecting Intake and Digestibility of Forages by

Ruminants." J. Anim. Sci. 73(9):2774-2790.

Moore, J. E., M. H. Brant, W. E. Kunkle and D. I. Hopkins. 1999. "Effects of Supplementation on Voluntary Forage Intake, Diet, Digestibility, and Animal Performance." J. Anim. Sci. 77(Suppl. 2):122-135.

Pond, W. G., D. C. Church, K. R. Pond, and P. A. Schoknecht. 2005. Basic Animal Nutrition and Feeding. Fifth Edition. Hoboken, NJ: John Wiley and Sons.

Van Soest, P. J. 1964. "Symposium on Nutrition and Forage and Pastures: New Chemical Procedures for Evaluating Forages." J. Anim. Sci. 23(3):838-845.

West, J. W., G. M. Hill, J. M. Fernandez, P. Mandebvu, and B. G. Mullinix. 1999. "Effects of Dietary Fiber on Intake, Milk Yield, and Digestion by Lactating Dairy Cows during Cool or Hot, Humid Weather." J. of Dairy Sci. 82(11):2455-2465. 